\title{
Influence of Hydraulic Domain on Vibration Control and Overload Prediction of High-Speed Punching Press: Multidomain Modelling and Experiment
}

\author{
Teng Xu, ${ }^{1,2}$ Qinxiang Xia $\left(\mathbb{D},{ }^{3}\right.$ Xiaoyu Wu, ${ }^{1}$ Jiaqi Ran, ${ }^{1}$ Feng Gong, ${ }^{1}$ and Chunying Lee ${ }^{4}$ \\ ${ }^{1}$ College of Mechatronics and Control Engineering, Shenzhen University, Shenzhen 518060, China \\ ${ }^{2}$ National Engineering Research Center of Near-Net-Shape Forming for Metallic Materials, South China University of Technology, \\ Guangzhou 510640, China \\ ${ }^{3}$ Guangdong Provincial Key Laboratory of Precision Equipment and Manufacturing Technology, \\ School of Mechanical and Automotive Engineering, South China University of Technology, Guangzhou 510640, China \\ ${ }^{4}$ Department of Mechanical Engineering, National Taipei University of Technology, Taipei 10608, Taiwan
}

Correspondence should be addressed to Qinxiang Xia; meqxxia@scut.edu.cn

Received 21 June 2019; Accepted 1 August 2019; Published 19 September 2019

Academic Editor: Andrea Spaggiari

Copyright (c) 2019 Teng Xu et al. This is an open access article distributed under the Creative Commons Attribution License, which permits unrestricted use, distribution, and reproduction in any medium, provided the original work is properly cited.

By the multidomain modelling method, the vibration of a high-speed punching press was modelled and simulated, and the influence of the hydraulic system on the vibration of the punching press and the protection efficiency of the punching press under the overload condition was discussed. The multidomain simulation results were compared with the experimental results to the validity of the multidomain model on a punching press with a hydraulic system for vibration reduction function.

\section{Introduction}

With the continuous increasing stroke of a punching press, the complex inertia force generated by the movement of the crank-slider mechanism of the punch press will increase by square multiples $[1,2]$. This is the main reason for the vibration of the high-speed punching press and will eventually lead to the reduction of punching accuracy [3].

Vibration of the system of a punching press is closely related to the mechanical, control, electronic, hydraulic, and other parts of the whole punching press. Among which, the measures of reducing vibration by adopting hydraulic system, with characteristics of cushioning and small impact, have been widely used in major punching press. The parameters of the variables of the punching press can be adjusted according to the numerical simulation on working condition of the punching press in order to alleviate the vibration condition of the punch. Chen et al. [4] analysed the structure, working principle, and cushioning process of the hydraulic shock absorber, by which the shock absorption effect was finally elaborated. Li et al. [5] proposed a hydraulic vibration and noise reduction device consisting of a buffer cylinder, a buffer rod, and an accumulator, which can be used to reduce the instantaneous vibration of the sheet metal breaking during the punching process of a mechanical press. Finally, the main technical parameters of the hydraulic buffer cylinder were determined, and the method of dynamic analysis of the punching press was achieved. Liu et al. [6] studied the principle and operation process of an overload protection device which causes the external unloading circuit to unload when the pressure of the built-in hydraulic cushion of the slider exceeds the set load. Li et al. [7] proposed a slider hydraulic overload protection device for high-speed press, and the device structure was analysed combining with the development example of high-speed press. However, all the above-mentioned research on hydraulic shock absorber and hydraulic overload protection device belongs to the level of theoretical analysis. At present, 
there are few dynamic simulation studies on hydraulic shock absorber and hydraulic overload protection device of stamping equipment.

In this research, the influence of the installation of the hydraulic system on vibration reduction of a certain punching press was explored based on the unified multidomain modelling and simulation method, and the influences of hydraulic system parameters on vibration quantity were analysed as well.

\section{Research Object}

Figure 1 shows the closed four-point structure of the highspeed punching press considered in this study, including an upper crossbeam, side column, lower crossbeam, movable crossbeam, servomotor, gear set, slider, two crankshafts, four connecting rods, four lead screws, and four hydraulic cylinders [8], which is specially used to produce air-conditioning heat exchanger fins (as shown in Figure 2) [9].

\section{Multidomain Modelling of High-Speed Punching Press}

A multidomain model of the punching press was established (see Figure 3) considering the structure of comopnents of the punching press, and a physical object-oriented modelling method was selected and developed using the multidomain system dynamics platform SimulationX. The model includes control system, servomotor, inertia block and inertia database, displacement sensor, and mechanism components [10]. Damping and stiffness coefficients are set at the bed base, transmission screw, and connecting rod. The foundation is concrete foundation block with a size of $2.4 \mathrm{~m} \times 3.3 \mathrm{~m} \times 1.4 \mathrm{~m}$, and punch motor is EMB-1ED A15 series synchronous servomotor.

In this paper, a hydraulic cylinder is installed on each of the four vertices of the crossbeam of the high-speed punching press to connect with the moving crossbeam, which is used to adjust the position of the moving crossbeam in the vertical direction to adjust the height of the die. In addition, the hydraulic system can also absorb and eliminate the inertia force and stamping force of the slider and crankshaft which would be transmitted to the moving crossbeam, so as to prevent the die and punch from being damaged by overload under special circumstances [11]. A three-position four-port electromagnetic reversing valve was used to control the pushing rod motion of the cylinder in three kinds of situations: pushing out, contracting, and stopping. The schematic diagram of the hydraulic system and the parameters of the hydraulic components are shown in Figure 4 and Table 1, respectively.

Under the normal load, the guide screw provides upward tension to the upper crossbeam. The hydraulic cylinder enhances the balance of the high-speed punch by buffering and absorbing inertia force and stamping force of the motion mechanism, so as to reduce the vibration of the punch [12]. Under the overload load condition, the overload force would be applied on the hydraulic cylinder through the

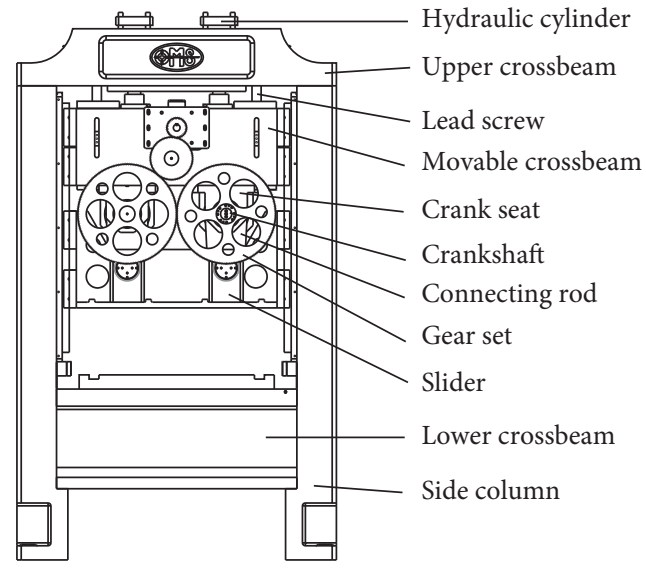

FIgURE 1: High-speed precision servo punching press [8].

movable crossbeam, and when the jacking force in the upward direction which is loaded on the cylinder exceeds the prescribed limit, the hydraulic cylinder unloads, following the movable crossbeam, and the piston of the hydraulic cylinder moves upward for a certain distance under the action of the overload upward, thus avoiding the slider and the die from continuing to move downward and bear the overload load.

Based on the multidomain model of a punch press under normal load as shown in Figure 3(a), the multidomain model of the punch press and die under overload load was established. With the mechanics MBS forces (multibody force unit) model library [13], a set of forces with the values both $879200 \mathrm{~N}$ and with opposite direction were applied on the upper and lower dies of progressive die of punch press, to represent the external load that causes sudden increase in die load during sudden events (see Figure 3(b)). Due to the overload load, the total force acting on the slider in the vertical direction exceeds the nominal pressure of the punch press by $1600 \mathrm{KN}$.

\section{Multidisciplinary Simulation Results of High-Speed Precision Punch}

In this paper, a coordinate system considering the above dead point as the starting point of time and the position of the upper dead point as the zero point of the slider displacement is established.

4.1. Under Normal Loading. Figure 5(a) shows the displacement curve of the slider and frame of the punch press with the hydraulic system installed. The relative distance between the equilibrium positions and the difference in amplitude of the slider and frame can be calculated as 0.008 and $0.012 \mathrm{~mm}$, respectively. Figure 5(b) shows the displacement time curve of the slider and the frame of the punch press without the installation of hydraulic cylinder. As shown in Table 2, the vibration of the punch before and after the installation of the hydraulic cylinder is compared. With the installation of hydraulic cylinder, the vibration of the punch press reduces by $45 \%$. 

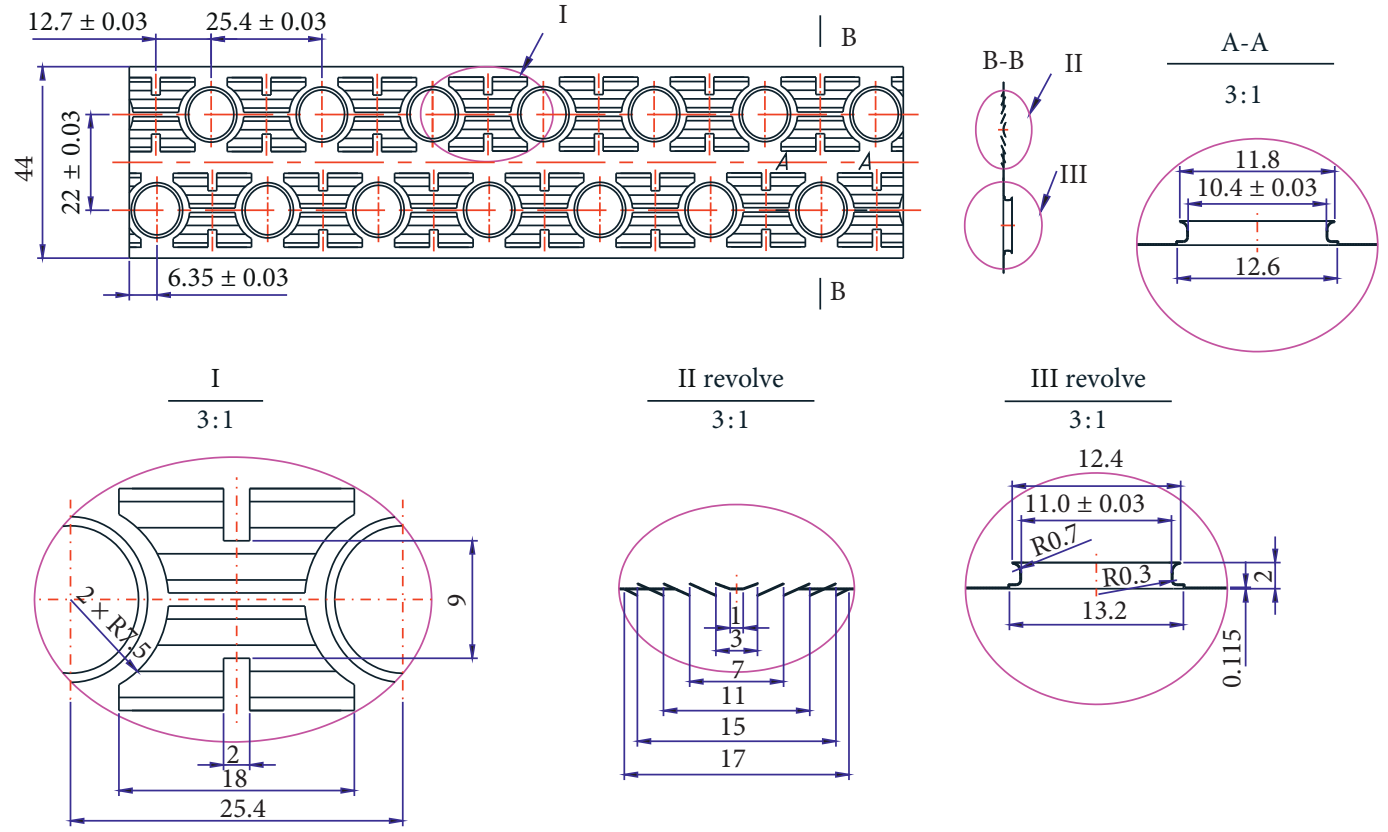

|B

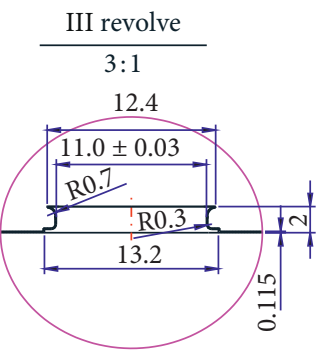

Figure 2: Heat exchanger fin.

4.2. Under Overload Loading. The purpose of the multidisciplinary simulation of high-speed punching press under overload loading is to predict the protective effect of the hydraulic system on the punching press through avoidance of hydraulic cylinder in emergency.

The response curve of the hydraulic system under overload loading is shown in Figure 6. The displacement curve of the piston rod in Figure 6(a) shows that the piston rod begins to fluctuate to a great extent from the 25th second, and it begins to fall back until the 26th second, delaying one second; after the 26th second, the piston rod even moves downward to the position that it stayed at the 25 th second, due to the large fluctuation of the piston rod. It shows that in emergency, the main parts of punch, such as slider, will still bear serious overload loading. The overload protection of hydraulic system parameters for dies needs to be further improved.

Figure 6(b) shows the hydraulic pressure curve of rodless cavity of the hydraulic cylinder under overload loading, the maximum pressure in the rodless cavity of the hydraulic cylinder reached $3.5 \mathrm{MPa}$, which exceeded the overflow threshold of $1.16 \mathrm{MPa}$ that set connected with the hydraulic cylinder [14]. This is because the maximum flux of the overflow valve is less than the hydraulic discharge flow, resulting in the overpressure of the hydraulic pressure.

\section{Experimental Verification}

The acceleration of the servo punch under no-load condition with the motor speed of $1500 \mathrm{rpm}$ was measured by DH5923 dynamic signal testing and analysis system (as shown in Figure 7). The vibration displacement curves of the bed and slider were obtained by integrating of the acceleration curves. The crankshaft speed of the high-speed punch is measured by using E6CP photoelectric sensor [15], as shown in Figure 8.
Figure 9 shows the multidomain simulation curve and experimental measurement curve of the vibration displacement curves of the slider and the frame with the motor speed of $1200 \mathrm{rpm}$. As shown in Figure 9(a), the experimental amplitude of the slider was $20.662 \mathrm{~mm}$, and the simulated value of that was $20.376 \mathrm{~mm}$, with a relative error between which was $1.36 \%$. As shown in Figure 9(b), the vibration amplitude of the frame is $0.769 \mathrm{~mm}$, and the simulated value of that was $0.687 \mathrm{~mm}$, with a relative error of $13.86 \%$.

Figure 10 shows the experimental and simulated speed curves of the crankshaft with the motor speed of $1200 \mathrm{rpm}$. The theoretical crankshaft speed is $240 \mathrm{rpm}$, and the measured crankshaft speed fluctuated between $234 \mathrm{rpm}$ and $246 \mathrm{rpm}$. As shown in Figure 10(a), the fluctuation of the experimental amplitude was $12 \mathrm{rpm}$. The simulated speed of the crankshaft fluctuated between $236 \mathrm{rpm}$ and $244 \mathrm{rpm}$, as shown in Figure 10(b). The maximum relative error between the theoretical value and the measured value is $0.90 \%$, and the fluctuation amplitude is $8 \mathrm{rpm}$.

\section{Influence of Hydraulic Parameters on Vibration and Overload Protection}

6.1. Effect on Vibration of Punch Press under Normal Load. Table 3 shows the corresponding vibration of punching press under different pressure of hydraulic pump. It reveals that the vibration balance point of the frame translated from the above position to the below position of the balance point of the slider, when a certain pressure of the pump was set. This is because the hydraulic force loads directly on the slider, which results in the decrease of the vibration balance point of the slider, while the hydraulic force acts on the frame indirectly. Therefore, the influence on the equilibrium point of frame is less than that on the slider. 


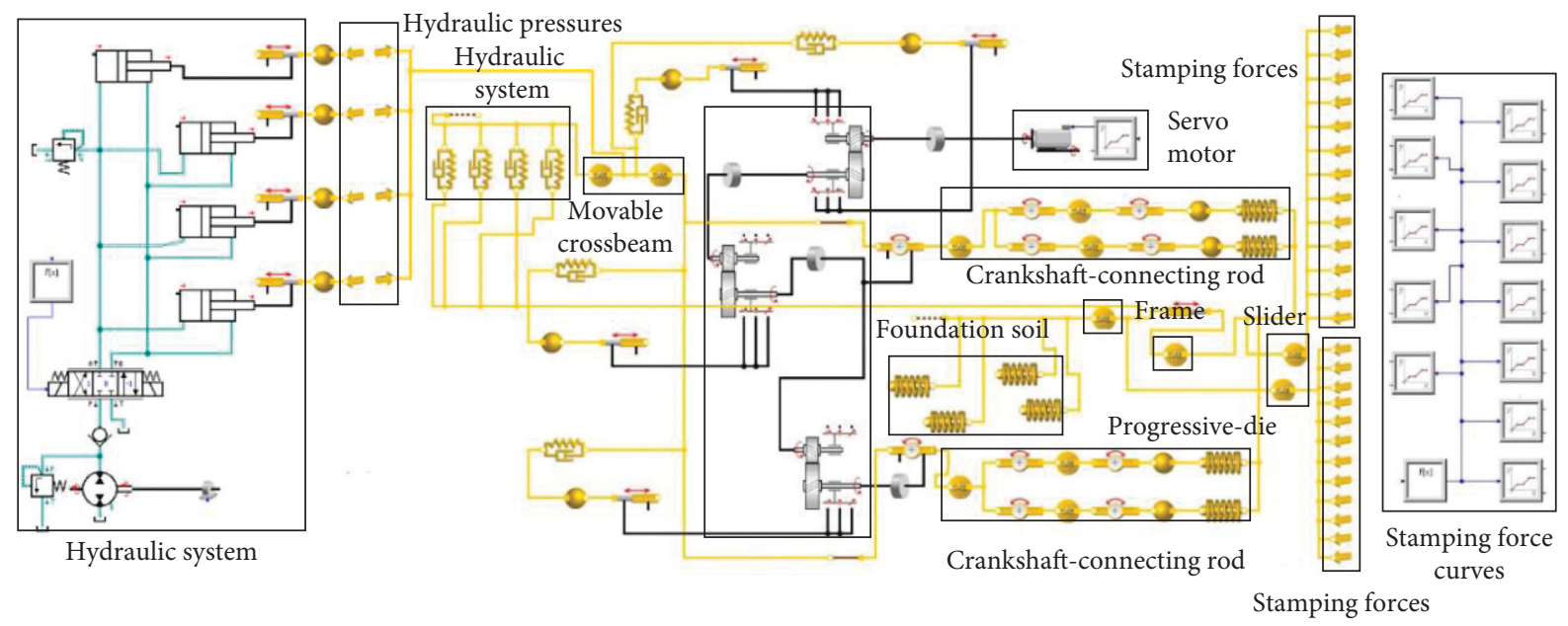

(a)

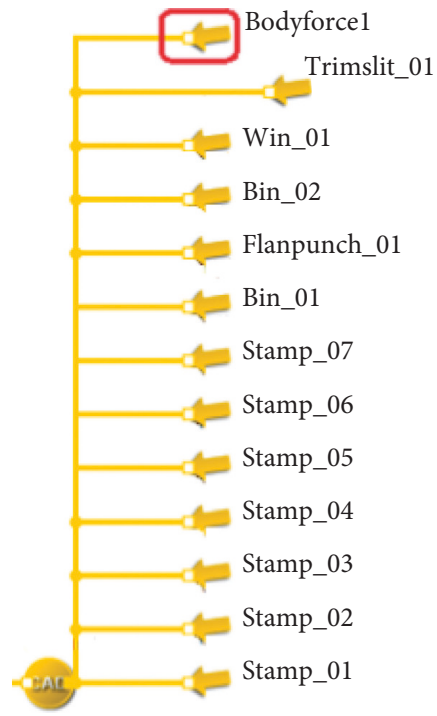

(b)

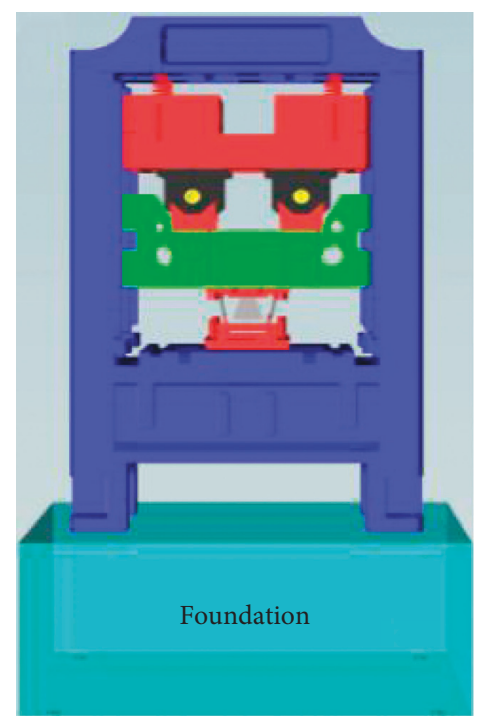

(c)

FIGURe 3: Multidomain model of high-speed punching press. (a) Component structure of multidomain model of punching press. (b) Application of load in emergencies. (c) 3D view of multidomain model.

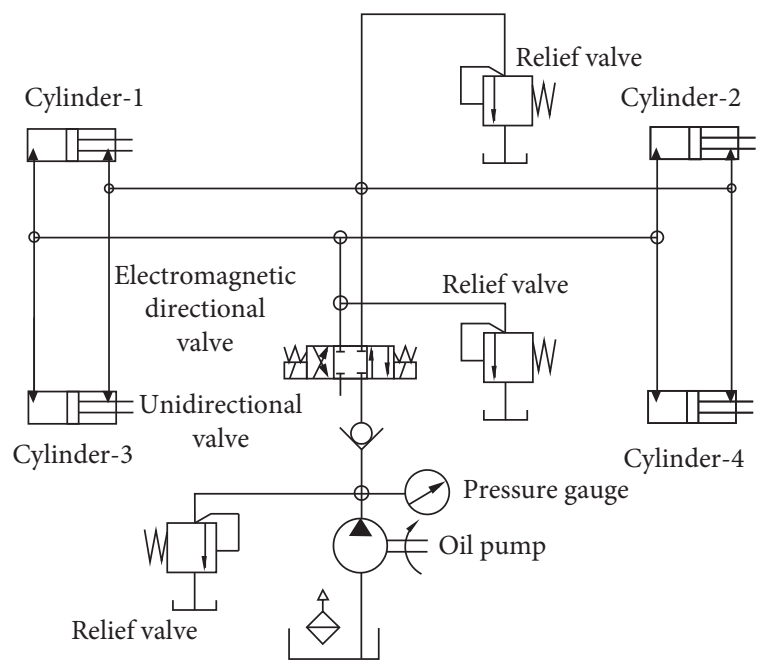

FIgURE 4: Schematic diagram of hydraulic subsystem.
Before installation of the hydraulic system, the vibration quantity of the punch is mainly composed of the distance between the equilibrium position of the frame and the slider; after the installation of the hydraulic system with the pressure of $20000 \mathrm{~Pa}$, the distance between the equilibrium position of the frame and the slider decreases, while the difference between the amplitudes of which increases; the hydraulic system conveys the hydraulic pressure in vertical downward to the movable crossbeam, and the force reaches its maximum and minimum value at the upper and lower dead points of the slider, respectively. As a result, the inertia forces of the slider and punch at the upper dead point decrease, and the inertia force at the equilibrium position increases to a greater extent, and the inertia force at the lower dead point increases to a lesser extent, which causes the equilibrium point of the frame and the slider to move downward to a certain extent. For the reason that the reduction of inertia forces of the slider and frame at the 
TABLE 1: Component parameters of hydraulic system.

\begin{tabular}{lccccc}
\hline \multirow{2}{*}{ Cylinder } & Model & Internal diameter & Piston rod outer diameter & Stroke & Pressure level \\
& HOB- $200 \times 200$ & $200 \mathrm{~mm}$ & $100 \mathrm{~mm}$ & $200 \mathrm{~mm}$ & $0 \sim 14 \mathrm{MPa}$ \\
\hline \multirow{2}{*}{ Relief valve } & Model & Path & Pressure regulation range & Maximum pressure & Maximum flow rate \\
& RF-G02-3-32 & $6 \mathrm{~mm}$ & $7 \sim 25 \mathrm{MPa}$ & $25 \mathrm{MPa}$ & $20 \mathrm{~L} / \mathrm{min}$ \\
\hline
\end{tabular}

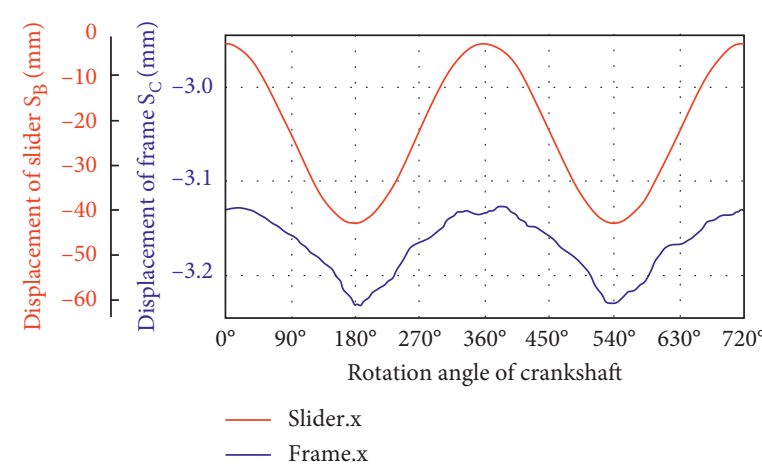

(a)

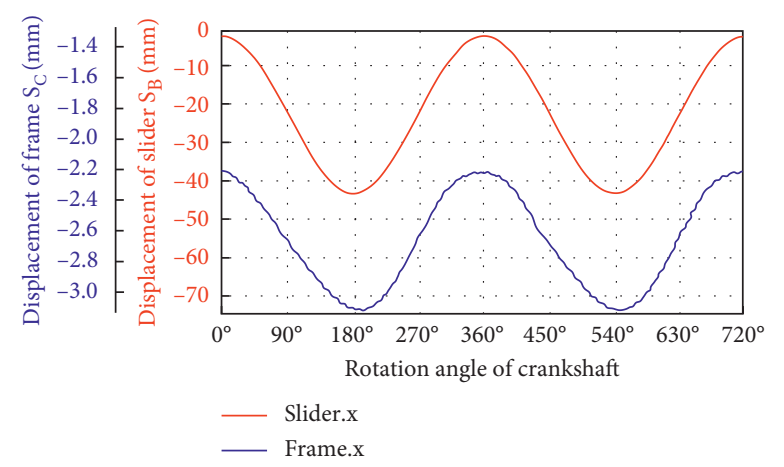

(b)

Figure 5: Vibration curves of the bed and slider before and after installation of hydraulic system. (a) Without installation of hydraulic system. (b) With installation of hydraulic system.

TABLE 2: Comparison of vibration quantity of punch press before and after installation of hydraulic system.

\begin{tabular}{|c|c|c|c|c|c|}
\hline $\begin{array}{l}\text { Installation of } \\
\text { hydraulic } \\
\text { system }\end{array}$ & $\begin{array}{l}\text { Vibration amplitude/ } \\
\text { equilibrium position of } \\
\text { frame }(\mathrm{mm})\end{array}$ & $\begin{array}{l}\text { Vibration amplitude/ } \\
\text { equilibrium position of } \\
\text { slider }(\mathrm{mm})\end{array}$ & $\begin{array}{c}\text { Difference between } \\
\text { amplitudes of frame and } \\
\text { slider }(\mathrm{mm})\end{array}$ & $\begin{array}{c}\text { Relative distance } \\
\text { between equilibrium } \\
\text { positions of frame and } \\
\text { slider }(\mathrm{mm})\end{array}$ & $\begin{array}{c}\text { Relative } \\
\text { vibration } \\
\text { quantity }(\mathrm{mm})\end{array}$ \\
\hline Before & $0.446 /(-2.664)$ & $0.444 /(-22.637)$ & 0.002 & 0.027 & 0.029 \\
\hline After & $0.052 /(-3.178)$ & $0.040 /(-23.186)$ & 0.012 & -0.008 & 0.020 \\
\hline
\end{tabular}

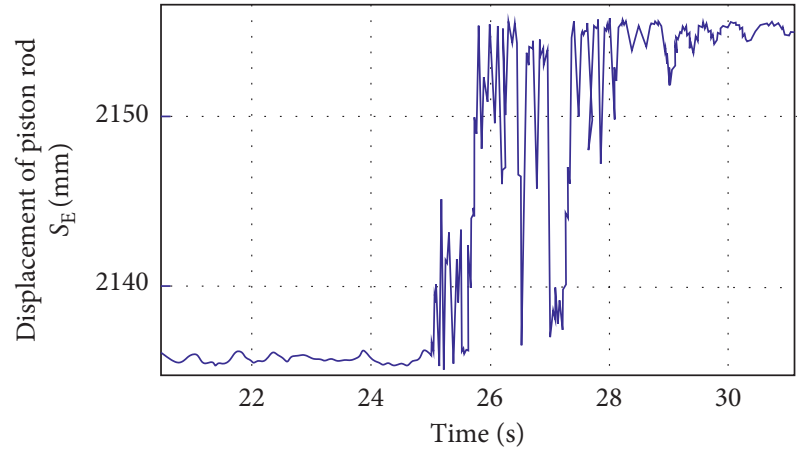

(a)

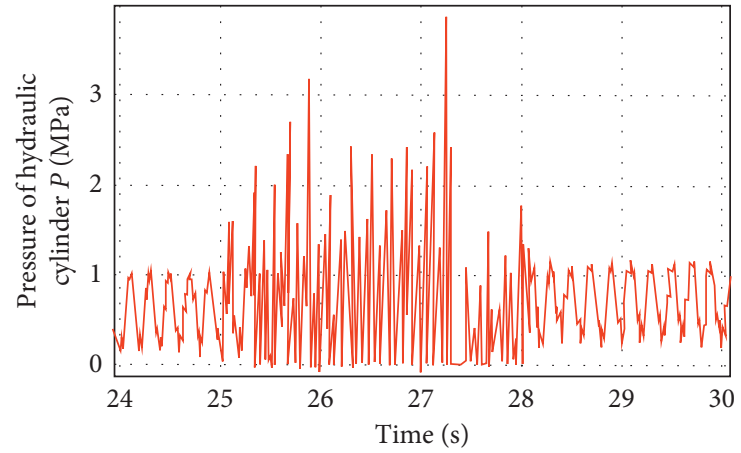

(b)

FIgUre 6: Pressure curve of rodless cavity under abnormal load. (a) Displacement curve of piston. (b) Pressure curve of hydraulic cylinder.

upper dead point was much greater than the increasing of that at the lower dead point, the amplitude of the slider and frame decreases.

When the pressure of the hydraulic pump increased to $40000 \mathrm{~Pa}$, the elimination effect of the hydraulic system on the total inertia force at the upper dead point of the slider and bed increases, and the elimination effect is greater than the enhancement of the hydraulic system on the total inertia force at the lower dead point. As a result, the vibration amplitude of both the frame and slider decreases, and the inertia force value of the slider and frame at the equilibrium position increases.
The equilibrium points of the slider and frame decreased, while the slider equilibrium points decreased more slowly; therefore, the distance between the equilibrium points of the slider and frame decreased. Because of the vibration superposition in the slider, its amplitude decreased faster than that of the frame; therefore, the difference between the vibration amplitude of the frame and the slider increased, and the relative vibration of the frame and the slider decreased by $10 \%$ comparing with the hydraulic pressure of $20000 \mathrm{~Pa}$.

When the pressure of the hydraulic pump increased to $60000 \mathrm{~Pa}$, similarly, the equilibrium points of the frame and 


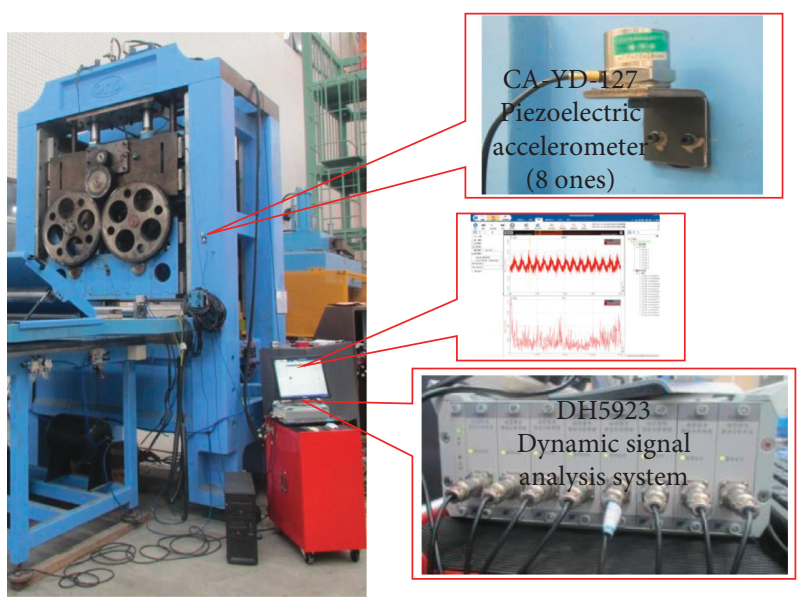

FIGURE 7: Acceleration test experiment of main parts.

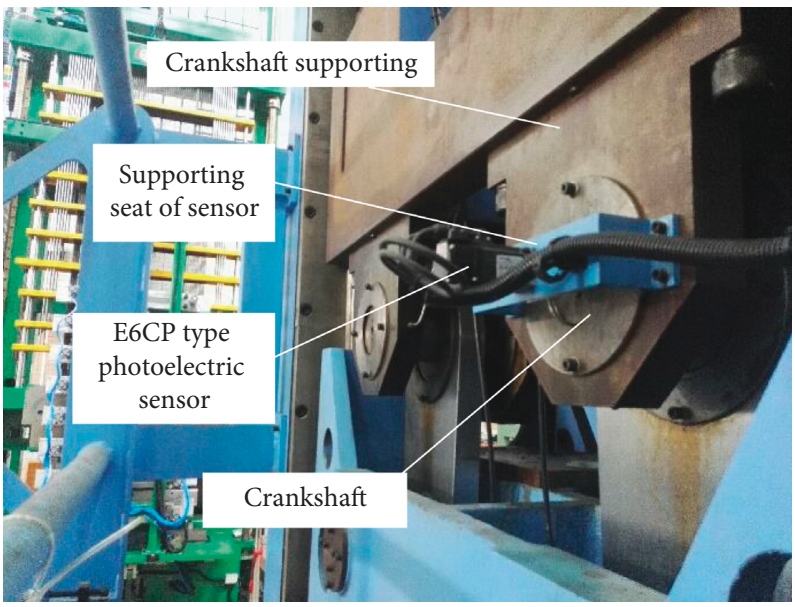

FIgURE 8: E6CP photoelectric speed sensor measuring tool.

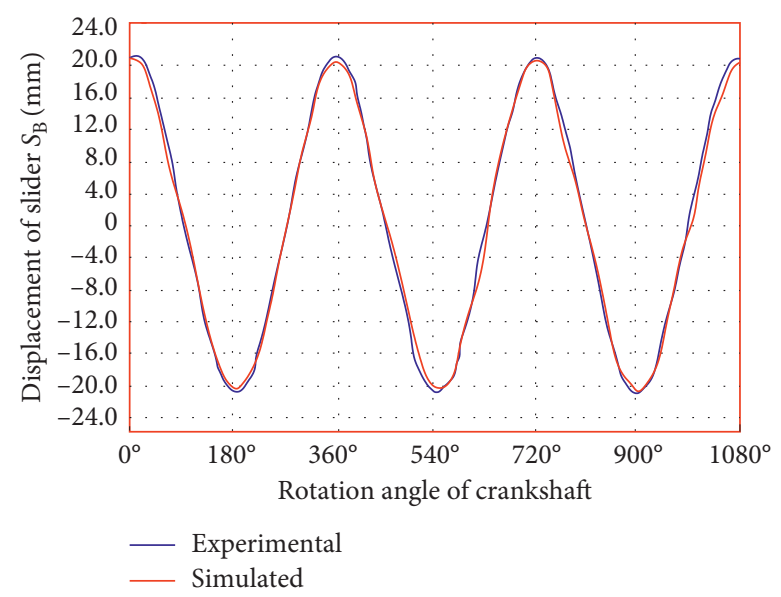

(a)

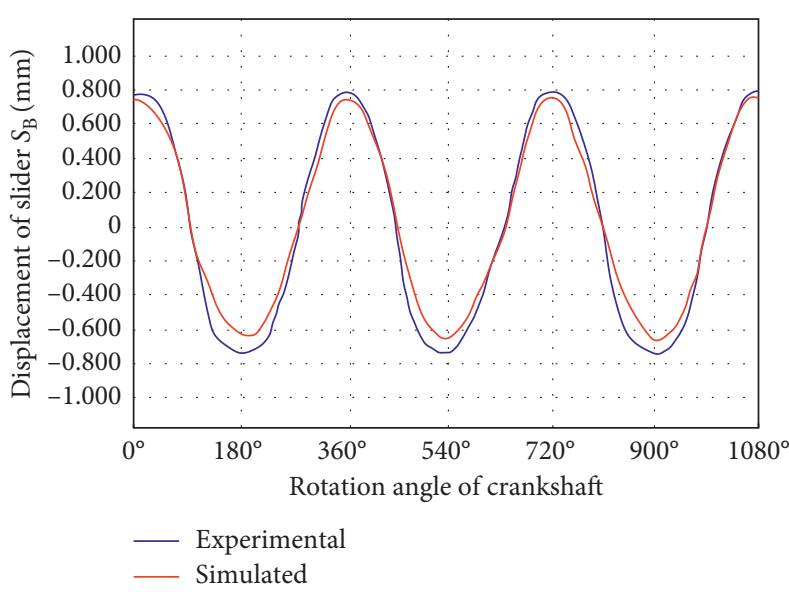

(b)

Figure 9: Experimental and simulated displacement curves of the slider and frame under the motor speed of $1200 \mathrm{rpm}$. (a) Displacement curve of the slider. (b) Displacement curve of the frame.

slider still moved down a certain distance, while the amplitudes of which increased. This is because with the increase of the pressure of the hydraulic pump, the output hydraulic pressure of the hydraulic cylinder increases gradually, and increasing of inertia force of the slider and upper moving beam at the lower dead point, the effect of the hydraulic 


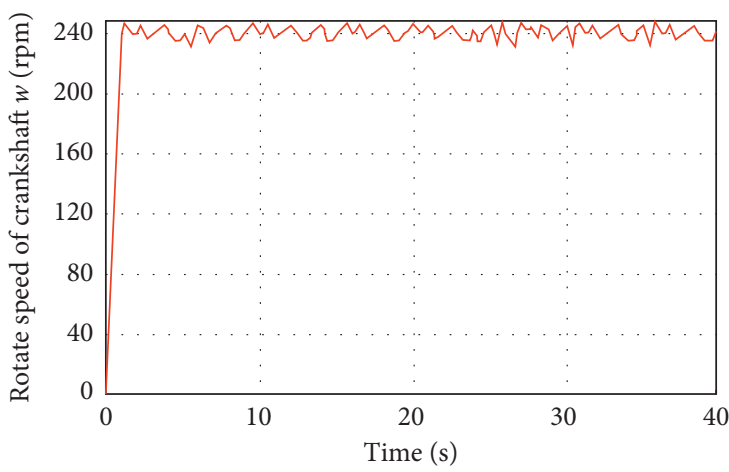

(a)

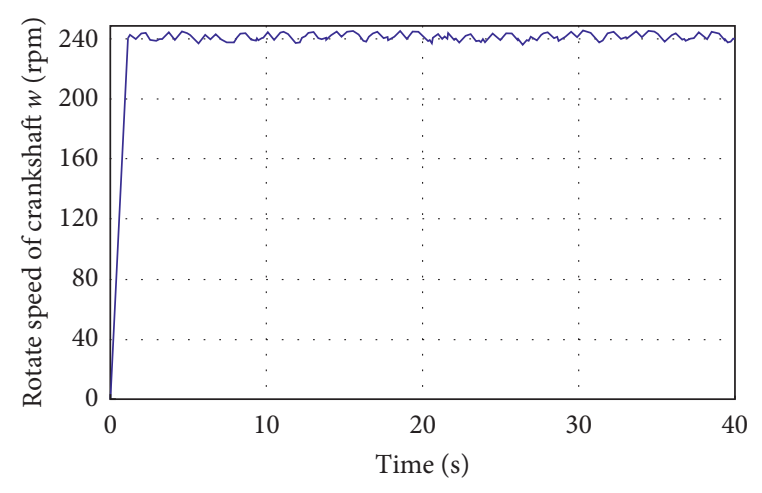

(b)

Figure 10: Crankshaft speed curve under the motor speed of $1200 \mathrm{rpm}$. (a) Experimental crankshaft speed curve. (b) Simulated crankshaft speed curve.

TABLE 3: Vibration of punching press under different pressure of hydraulic pump.

\begin{tabular}{|c|c|c|c|c|c|}
\hline $\begin{array}{l}\text { Pressure } \\
(\mathrm{Pa})\end{array}$ & $\begin{array}{l}\text { Vibration amplitude/ } \\
\text { equilibrium position of } \\
\text { frame }(\mathrm{mm})\end{array}$ & $\begin{array}{l}\text { Vibration amplitude/ } \\
\text { equilibrium position of } \\
\text { slider }(\mathrm{mm})\end{array}$ & $\begin{array}{l}\text { Difference between } \\
\text { amplitudes of frame and } \\
\text { slider }(\mathrm{mm})\end{array}$ & $\begin{array}{l}\text { Relative distance between } \\
\text { equilibrium positions of } \\
\text { frame and slider ( } \mathrm{mm})\end{array}$ & $\begin{array}{c}\text { Relative } \\
\text { vibration } \\
\text { quantity }(\mathrm{mm})\end{array}$ \\
\hline- & $0.446 /(-2.664)$ & $0.444 /(-22.637)$ & 0.002 & 0.027 & 0.029 \\
\hline 20000 & $0.052 /(-3.178)$ & $0.040 /(-23.186)$ & 0.012 & -0.008 & 0.020 \\
\hline 40000 & $0.050 /(-3.186)$ & $0.037 /(-23.191)$ & 0.013 & -0.005 & 0.018 \\
\hline 60000 & $0.051 /(-3.195)$ & $0.039 /(-23.207)$ & 0.012 & -0.012 & 0.024 \\
\hline
\end{tabular}

pressure is gradually equal to the decreasing of inertia force of that at the up dead point. And the elimination effect of the hydraulic system on the inertia force of the punching press is gradually reduced, that is, the vibration reduction effect is also beginning to decrease; therefore, the relative vibration between the slider and frame no longer decreased. From the above analysis, it can be seen that the optimum hydraulic pump pressure of the high-speed punch hydraulic system is between $20000 \mathrm{~Pa}$ and $60000 \mathrm{~Pa}$.

6.2. Protective Effect of Punching Press under Overload Loading. In this paper, the function of the relief valve of the hydraulic system is to make the pressure of the rodless chamber of the hydraulic cylinder remain constant. Under the overload loading, the relief valve unloads, part of the high-pressure liquid in rodless chamber flows back to the tank; therefore, the piston rod returns back a certain distance, so as to ensure the die would not be destroyed by the overload loading [16].

Under the condition of overload loading, the maximum pressure of the rodless chamber of the hydraulic cylinder exceeds the threshold of the relief valve that is connected with it, as shown in Figure 6(b), because the maximum flux of the relief valve is less than the hydraulic discharge flow rate. According to Bernoulli's theorem [17], the faster the flow rate in a fluid system, the smaller the pressure produced by the fluid. In order to improve the response rate of the protection function of the hydraulic system under the overload loading, the flow rate of the relief valve was increased.
Figure 11 shows the displacement time curves of the piston rod when the overflow threshold was $1.16 \mathrm{MPa}$ and the pressure drop was $0.05 \mathrm{MPa}$; under the overload loading, the overflow velocity of $500 \mathrm{~L} / \mathrm{min}, 330 \mathrm{~L} / \mathrm{min}$, and $160 \mathrm{~L} /$ min were chosen, respectively. When the overflow velocity was set as $160 \mathrm{~L} / \mathrm{min}$, the simulated back time of the piston rod of the hydraulic cylinder was $0.8 \mathrm{~s}$, and it fluctuated 4 times before the piston rod returns back; because of the influence of the pressure variation of the rod chamber, the piston rod moves downward again during the back stroke of the piston rod between 26.5-27.4s, which makes the slider and the die return to the position for stamping work. At that condition, the slider connecting rod, crankshaft, and other components still have the possibility of bearing overload loading. When the overflow velocity is $330 \mathrm{~L} / \mathrm{min}$, the back time of the piston rod was shorter because of the increase of pressure in the rodless chamber, but the return distance was not obvious, and the stability of the piston rod is poor after the short return distance, with a more violent vibration. The overflow velocity of $160 \mathrm{~L} / \mathrm{min}$ as well as $330 \mathrm{~L} / \mathrm{min}$ cannot achieve the purpose of overload protection. When the overflow velocity was $500 \mathrm{~L} / \mathrm{min}$, the return time of the piston rod decreased to $0.4 \mathrm{~s}$, and it fluctuated only 2 times before the piston rod returns back. Due to the influence of the pressure variation of the rod chamber, although the piston rod still has a downward displacement, it kept a return distance over $10 \mathrm{~mm}$, and its vibration fluctuation was relatively stable, which could effectively protect the die and punch from being overloaded.

Figure 12 shows the displacement curve of the piston rod when the overflow threshold was $1.16 \mathrm{MPa}$ and the overflow 


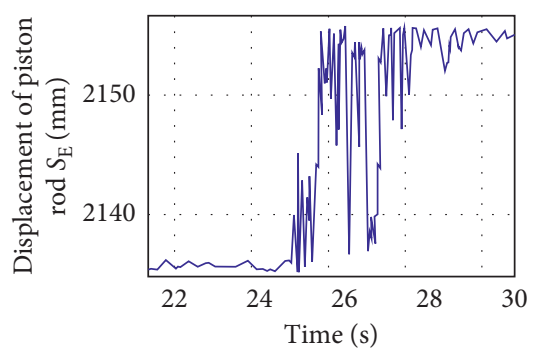

(a)

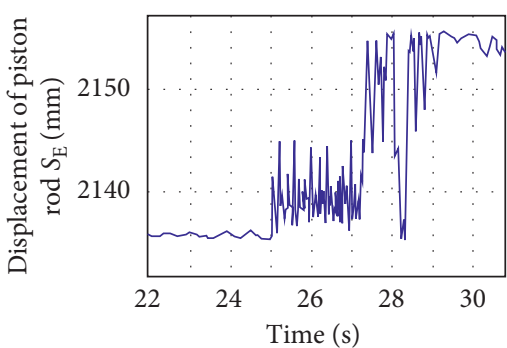

(b)

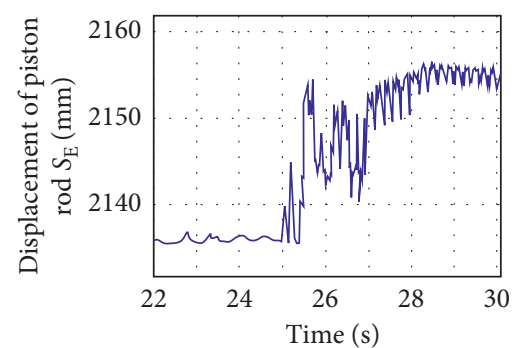

(c)

Figure 11: Influence of overflow velocity on displacement time curves of the piston rod under overload loading. (a) $160 \mathrm{~L} / \mathrm{min}$. (b) $330 \mathrm{~L} / \mathrm{min}$. (c) $500 \mathrm{~L} / \mathrm{min}$.

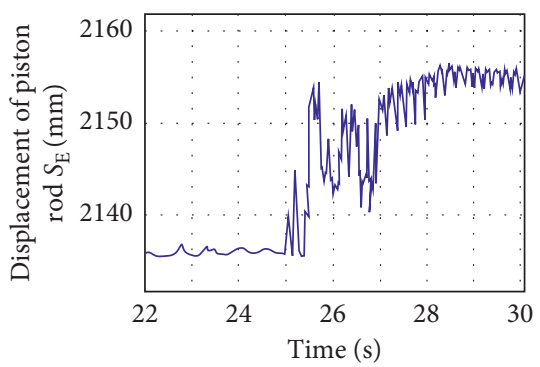

(a)

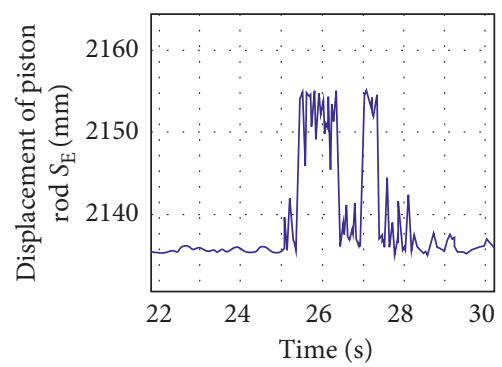

(b)

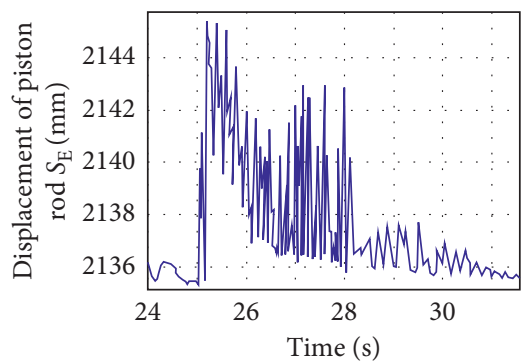

(c)

FIGURE 12: Influence of pressure drop on displacement time curves of the piston rod under overload loading. (a) $160 \mathrm{~L} / \mathrm{min}$. (b) $330 \mathrm{~L} / \mathrm{min}$. (c) $500 \mathrm{~L} / \mathrm{min}$.

velocity was $500 \mathrm{~L} / \mathrm{min}$; under the overload loading, the pressure drop of $0.05 \mathrm{MPa}, 0.1 \mathrm{MPa}$, and $0.2 \mathrm{MPa}$ were explored, respectively. When the pressure drop was $0.05 \mathrm{MPa}$, the return back time of the piston rod was $0.4 \mathrm{~s}$; when the pressure drop decreased to $0.2 \mathrm{MPa}$, the return back time was reduced to $0.2 \mathrm{~s}$, and the number of vibration fluctuations of the piston rod before returning back was reduced from 2 to 1 .

Due to the increase of the pressure drop, the pressure of the rodless chamber of the hydraulic cylinder raised firstly and then decreased rapidly under the overload loading, resulting in the increase of the response speed of the piston rod and the decrease of the vibration times before it returns back. However, when the pressure drop was too large, rapid decrease in pressure of the rodless chamber would appear, and subsequently, the hydraulic pressure of the rodless chamber increases when the hydraulic pump supplies the hydraulic oil to the rodless chamber, causing the piston rod to move downward with a greater degree of vibration, which results in instability. Therefore, simply increasing the pressure drop can not effectively increase the response speed of the piston rod.

\section{Conclusions}

According to the structure characteristics of the precision high-speed punching press, the multidomain modeling and simulation of which were carried out. The effect of the installation of the hydraulic system on the vibration reduction of the punching press under normal working condition was studied, and the influence of hydraulic parameters on the vibration reduction and overload protection of the punching press was explored. The following conclusions are drawn:

(1) Under the normal punching loading, the average inertia force of the slider and the frame at their upper and lower dead points could be reduced by providing a certain value of hydraulic pressure to the moving crossbeam in order to achieve the vibration reduction of the punching press.

(2) Under the normal punching loading, the increase of pressure in the hydraulic system can reduce the average inertia force of the slider and frame to a certain extent. However, when the pressure of the hydraulic system increases to a certain value, the increasing of the inertia force of the slider at the lower dead point would exceed the decreasing of the inertia force at the upper dead point, which is not conducive to the reduction of vibration.

(3) Aiming at the overload loading on the punching press during high-speed stamping, increasing the overflow velocity of the relief valve can increase the return speed and quantity of the piston in the hydraulic cylinder to protect the punching press and stamping die. Furthermore, increasing the pressure drop of the relief valve to a certain range can improve the return speed and the motion stability of the piston rod; when the pressure drop increases to a certain extent, it would lead to the excessive change 
of pressure in the rodless chamber, which would cause the instability of the piston rod.

\section{Data Availability}

No data were used to support this study.

\section{Conflicts of Interest}

The authors declare that there are no conflicts of interest regarding the publication of this paper.

\section{Acknowledgments}

The authors would like to thank the funding support from the Produce-Learn-Research Major Project of Education Ministry in Guangdong (no. 2012B091000128), and the Project of Guangdong Provincial Key Laboratory of Precision Equipment and Manufacturing Technology (no. PEMT1202), the Open Funds of National Engineering Research Center of Near-Net-Shape Forming for Metallic Materials (no. 2016006), and the Research Project of State Key Laboratory of Mechanical System and Vibration (Project no. MSV201915), National Taipei University of Technology-Shenzhen University Joint Research Program (Project no. 2019010), the Natural Science Foundation of Shenzhen University (Grant no. 2019042), and the National Natural Science Foundation of China (Grant no. 51705333).

\section{References}

[1] H. Mori, S. Nakamura, F. Ono, K. Kariya, and S. Umezawa, “A study on characteristics of cooling heat transfer of supercritical pressure fluids in a plate heat exchanger," Heat Transfer Engineering, vol. 37, no. 7-8, pp. 659-667, 2016.

[2] A. Gut'es, C. Carraro, and R. Maboudian, "Silver dendrites from galvanic displacement on commercial aluminum foil as an effective SERS substrate," Journal of the American Chemical Society, vol. 132, no. 5, pp. 1476-1477, 2010.

[3] T. Xu, Q.-X. Xia, J. Long, and X. Long, "A study on multidomain modeling and simulation of precision high-speed servo numerical control punching press," Proceedings of the Institution of Mechanical Engineers, Part I: Journal of Systems and Control Engineering, vol. 232, no. 7, pp. 830-844, 2018.

[4] F. Chen, "Study on the test of hydraulic vibration absorber of mechanical press," Engineering Technology: Full Text Edition, vol. 2016, no. 3, Article ID 00283, 2016.

[5] Z. Li, Y. Li, Q. Guo et al., "Experimental study on hydraulic shock absorber of mechanical press," Forging Technology, vol. 1987, no. 2, pp. 40-44, 1987.

[6] F. Liu, X. Gao, and B. Yao, "Correct selection of hydraulic overload protection device for press," Hydraulic Pneumatic and Sealing, vol. 28, no. 3, pp. 34-35, 2008.

[7] J. Li, E. Wang, M. Zhihui et al., "Design and analysis of hydraulic overload protection structure for slider of highspeed press," Forging Equipment and Manufacturing Technology, vol. 40, no. 1, pp. 35-36, 2005.

[8] X. Xu, H. Tao, J. Han, and G. Buffa, "Shock mechanism analysis and simulation of high-power hydraulic shock wave simulator," Shock and Vibration, vol. 2017, Article ID 4361256, 10 pages, 2017.
[9] X. T. Hu, Design of multi-station progressive die for air conditioning heat exchanger fin, Ph.D. thesis, South China University of Technology, Guangzhou, China, 2013.

[10] A. Jomartov, "Model of two-link planar robot on SimulationX," Advanced Materials Research, vol. 1025-1026, pp. 897-901, 2014.

[11] K. Białas and A. Buchacz, "Hydraulic elements in reduction of vibrations in mechanical systems," IOP Conference Series Materials Science and Engineering, vol. 227, 2017.

[12] T. Nguyen, M. Elahinia, W. W. Olson et al., "A 6-DOF vibration isolation system for hydraulic hybrid vehicles," in Proceedings of the Smart Structures and Materials 2006: Damping and Isolation, San Diego, CA, USA, March 2006.

[13] A. Jomartov and A. Tuleshov, "Modeling dynamics of planetary gears of crank press on Simulationx," in Proceedings of the International Conference of IFToMM ITALY, Springer, Cassino, Italy, October 2018.

[14] S. Lei, Z. Yan-Zhe, W. Qing-Han et al., "Research on noise reduction of pilot relief valve," Chinese Hydraulics \& Pneumatics, vol. 2015, no. 4, 2015.

[15] H. Deng, "Design of data automatic acquisition system for accelerometer calibration," Electromechanical Engineering Technology, vol. 37, no. 5, pp. 60-62, 2008.

[16] R. Cioară, “"Hydraulic cushion” type overload protection devices usable in mechanical presses," A Patent Study, 2016.

[17] Department of Earth System Science and Technology, Interdisciplinary Graduate School of Engineering Sciences, Kyushu University, "Dynamics of Perfect Fluids," Fluid Dynamics for Global Environmental Studies, Springer, Tokyo, Japan, 2017. 


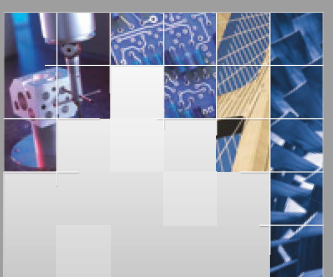

\section{Enfincering}
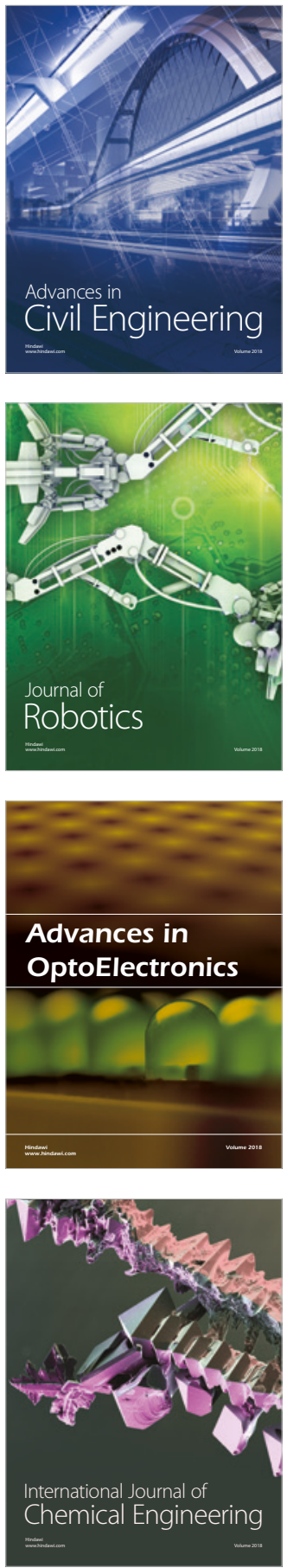

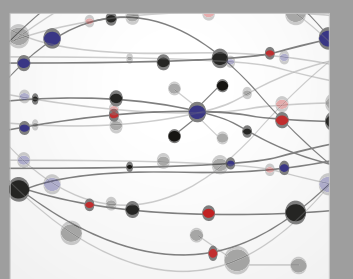

\section{Rotating \\ Machinery}

The Scientific World Journal

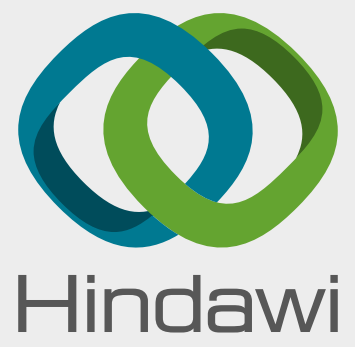

Submit your manuscripts at

www.hindawi.com
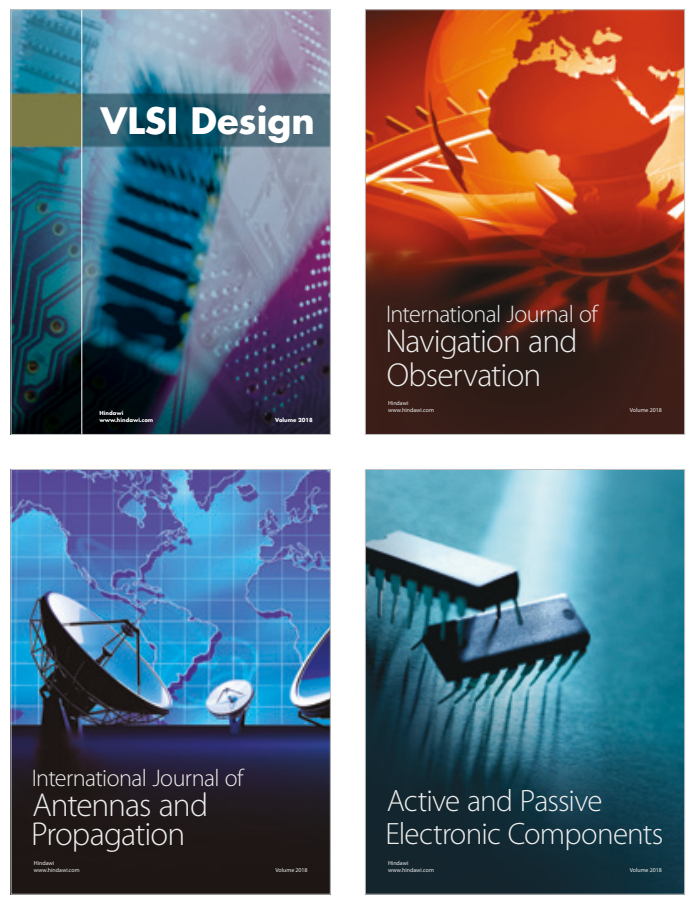
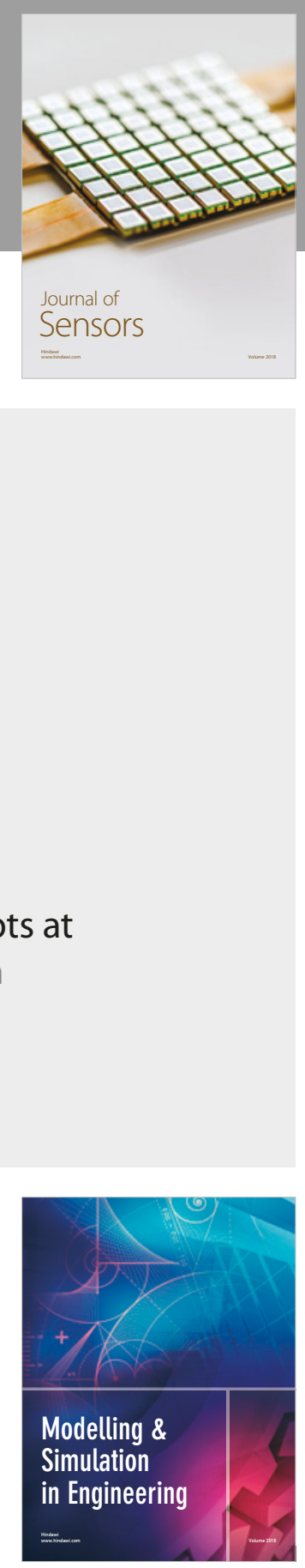

\section{Advances \\ Multimedia}
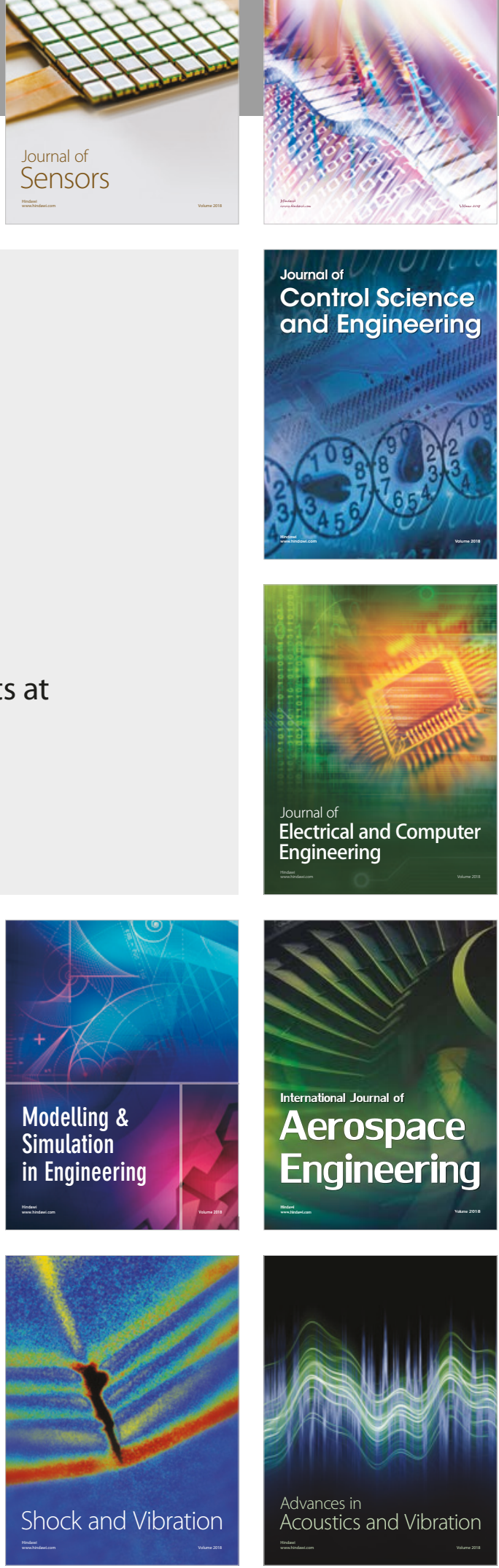